\title{
Inserção de professoras iniciantes em escolas públicas: um olhar sobre as práticas na Espanha
}

\author{
Marisa Narcizo Sampaio \\ Universidade Federal do Rio Grande do Norte
}

\section{Resumo}

Este artigo relata pesquisa realizada com o objetivo de conhecer como acontece, na prática cotidiana, a incorporação na escola pública dos novos professores na Espanha, onde o acompanhamento dessa fase inicial da docência está previsto por lei. Foram visitadas escolas e entrevistadas professoras no primeiro ano de atuação. As práticas identificadas, discutidas com base em Certeau, revelaram suas tensões e complexidade, especialmente nas relações entre o prescrito na legislação e a experiência vivida pelas professoras e, ainda, as dificuldades relatadas por elas, que perpetuam as apontadas pelos pesquisadores. Percebeu-se a necessidade de um programa de apoio completo e duradouro aos professores iniciantes.

Palavras-chave: Professoras iniciantes. Complexidade. Programa de apoio.

\section{Insertion of novice teachers in public schools: a look at the practices in Spain}

\section{Abstract}

This article reports a research carried out to know as it happens, in everyday practice, the incorporation of novice teachers into the public school in Spain, where law prescribes the follow up on this early stage of teaching. We visit schools and have interviewed teachers to reach this target in their first year of work. The practices identified, discussed based on Certeau, revealed its tensions and complexity, especially in the relations between the requirements of legislation and the experience lived by the teachers, and also the difficulties reported by them, that perpetuate that ones identified by researchers. We realized the need for a program of complete and lasting support to beginning teachers.

Keywords: Novice teachers. Complexity. Supporting program. 


\section{Inserción de maestras noveles encentros educativos públicos: una mirada a las prácticas en España}

\section{Resumen}

La investigación buscó saber que pasa en la práctica cotidiana de la incorporación de maestras noveles en los colegios públicos en Galicia, donde el seguimiento de esta fase inicial de la enseñanza está previsto en la ley. La investigación se hizo con visitas a colegios y entrevistas con maestras en su primer año de profesión. Las prácticas identificadas, discutidas con base en Certeau, revelaron sus tensiones y complejidad, especialmente entre lo que establece la legislación y la experiencia vivida por las maestros, y también entre las dificultades señaladas por ellos, que perpetúan las identificadas por investigadores. Se siente la necesidad de un programa de apoyo completo y duradero los maestros noveles.

Palabras clave: Maestras noveles. Complejidad. Programa de apoyo.

No processo de nos tornarmos professores e professoras, aprendemos e produzimos novos conhecimentos em diversos contextos: na nossa educação

37 básica; na formação inicial nos cursos de formação de professores e professoras; como profissionais no contato e na relação com as alunas e os alunos; nos momentos de troca com outros profissionais da escola, com a comunidade do entorno da escola (em momentos informais ou planejados); nas relações da vida fora do ambiente de trabalho; com a reflexão sobre a prática; com o estudo e discussão sobre as experiências e as teorias; com a participação e a discussão sobre os acontecimentos socio político-econômicos (SAMPAIO, 2008). Assim, entre tantos contextos de aprendizagem, podemos afirmar que a etapa inicial e formal do processo de se tornar professor e professora, nos cursos de formação de professores, não é suficiente, e que a formação continuada é imprescindível.

Nessa perspectiva, destaco o início da atuação docente como uma fase peculiar desse processo contínuo de formação, já que o profissional, iniciante na carreira docente, precisa mobilizar uma série de aprendizagens para enfrentar os desafios da prática pedagógica que podem se transformar em dificuldades. Dessa forma, a preocupação com as práticas de formação continuada, nessa etapa, se justifica pela necessidade de atenção, de acompanhamento e de programas que auxiliem na integração dos novos docentes à rotina e à cultura da profissão, tal como apontam diferentes autores: Guarnieri 
(2005); Huberman (2000); Imbernón (1 994); Marcelo Garcia (1999); Nono (2011).

Essas preocupações levaram-me a tentar investigar que possibilidades poderiam ser pensadas para a formação continuada do profissional que inicia sua carreira, tendo como foco a escola pública aqui concebida como espaço democrático a que todos devem ter acesso e possibilidade de expressão e de participação.

No Brasil, não há uma tradição de se realizar um acompanhamento especial no início da atuação docente na escola ou do desenvolvimento de programas formativos específicos para esses casos. Houve, em 2007, uma tentativa nacional com a elaboração do Projeto de Lei n 227, prevendo um período de Residência Pedagógica, com o acompanhamento do professor iniciante por um professor mais experiente, que orientaria seu trabalho e faria propostas para sua formação continuada. O projeto, porém, foi arquivado com o fim da legislatura, em 201 1, sem ser votado. Atualmente, está tramitando no Congresso Nacional, desde 2012, novo projeto de Lei que institui a obrigatoriedade da residência pedagógica como requisito para obtenção do título de professor. Apenas nas universidades federais existe um procedimento de acompanhamento e tutoria de docentes durante seu estágio probatório.

Na Espanha, a Lei Orgânica de Educação (LOE, 2006, equivalente à LDB brasileira), ressalta a importância e a necessidade da formação docente e trata, no seu artigo 101, da incorporação à docência nas escolas públicas dos professores e professoras novos, a ser realizada no primeiro ano de exercício profissional com acompanhamento de colegas com mais experiência que cumprem a função de tutores. Assim, considera que a formação inicial dos novos docentes será complementada e continuada com a tutoria e o acompanhamento desses colegas mais experientes.

A atual Lei Orgânica Espanhola (2013)', embora não trate tanto do tema da formação continuada do professorado, mantém, em seu discurso, a necessidade dessa formação para a melhoria da qualidade educativa e não altera o disposto na Lei anterior a respeito do acompanhamento dos professores iniciantes. A partir da LOE de 2006, foi publicado o Real Decreto de $n^{\circ} 276$, de 23 de dezembro de $2006^{2}$, que especifica o acompanhamento de todos os professores e professoras aprovados em concursos para a rede pública como profissionais em práticas, durante um período de três meses a um ano letivo, a 
ser adaptado e detalhado na organização dos concursos públicos por cada comunidade autônoma (equivalente aos estados brasileiros), de acordo com seu contexto.

Sabendo desse acompanhamento obrigatório aos professores iniciantes, interessei-me em conhecer o trabalho realizado pelas escolas da Espanha no cumprimento dessa legislação.

Neste artigo, relato o estudo feito com o objetivo de saber como se dá, na sua prática cotidiana, o acompanhamento da incorporação na escola pública dos novos profissionais; como as novas professoras sentem essa inserção; que mecanismos possuem escolas públicas para inserção e formação dos professores e professoras iniciantes. A fim de chegar a esse conhecimento, realizei visitas a escolas e entrevistas com professoras durante seu primeiro ano de atuação como professoras da rede pública de ensino na comunidade autônoma da Galícia. Em função disso, já é necessário esclarecer, inicialmente, que os dados aqui discutidos não se referem à Espanha como um todo, mas à Galícia, já que a pesquisa foi realizada em duas grandes cidades (A Coruña e Santiago de Compostela) dessa parte do Estado Espanhol, comunidade autônoma que possui cultura, língua e história próprias.

Busco aqui narrar de que maneira me aproximei dessa realidade e ainda discutir a constatação de que, como em todos os campos e acontecimentos da vida, nas propostas e nas práticas que conheci para o acolhimento de novos professores na escola pública galega, há tensões, contradições, complexidade. Entre essas tensões, destaco a relação entre o aspecto burocrático da legislação e a experiência positiva vivida pela maioria das professoras durante o período de práticas. Ressalto, ainda, a semelhança entre as dificuldades relatadas pelas professoras entrevistadas nesse início de carreira e aquelas apontadas pelos pesquisadores há, pelo menos, 30 anos.

\section{Aproximação com a realidade e suas práticas cotidianas}

Com a intenção de me aproximar da realidade e de suas práticas cotidianas, pensando que elas, com sua riqueza, vão muito além da letra da Lei, meu primeiro passo foi localizar escolas onde havia professoras iniciantes. Fiz uma busca na página eletrônica da Xunta de Galícia lgoverno da comunidade autônoma) para encontrar os últimos concursos realizados para professorado 
de Primária (equivalente no Brasil aos primeiros anos do Ensino Fundamental) e Educação Infantil. Encontrei o edital do concurso ocorrido no ano de 2013 para as seguintes especialidades: professores para acompanhamento de alunos com necessidades educacionais especiais (especialidade Pedagogia Terapêutica); professores para trabalhar em hospitais, centros sociais e escolas com o tratamento de dificuldades de leitura e fala (especialidade Audição e Linguagem); professores de língua inglesa para Educação Infantil e Primária; e professores para a Educação Infantil. O concurso também foi utilizado para translado de professores e professoras primárias, com experiência anterior.

Oedital foi publicado em quatro de abril de 2013 , as provas realizadas em julho e o resultado final, com a designação dos aprovados para sua lotação inicial e provisória, divulgado no mesmo mês. Os professores e professoras aprovados começaram a trabalhar no mês de setembro (início do ano letivo no hemisfério norte).

concurso foi constituído de uma prova teórica de conhecimentos pedagógicos (psicologia, didática e currículo) e duas provas práticas avaliadas por uma banca de cinco docentes. A primeira prova prática consistia na apresentação de um planejamento de aula. Na outra, o candidato ou candidata apresentava e defendia, durante 30 minutos, uma unidade didática elaborada para 15 dias, usando os materiais e recursos que julgasse necessários. Para essa apresentação, os candidatos e candidatas deviam preparar e levar 15 unidades didáticas, das quais, no momento da prova, eram sorteadas três para que o candidato ou candidata escolhesse uma para apresentar. Além disso, houve concurso de títulos, que pontuava experiência, cursos e publicações.

Esse primeiro passo do trabalho - identificar as escolas que tinham professores iniciantes no seu quadro - me permitiu também conhecer o que está oficialmente previsto para o início da atuação docente no ensino público.

Após esse processo, selecionei as escolas mais próximas, num tołal de cinco escolas nas cidades de A Coruña e Santiago de Compostela (cidades de mais fácil acesso, considerando minha localização), que tinham recebido professoras aprovadas nesse concurso. Dentre as especialidades contempladas pelo concurso (já mencionadas), escolhi fazer contato com as professoras de Educação Infantil, por ser uma das especialidades que formamos no curso de Pedagogia da Universidade Federal do Rio Grande do Norte a que estou vinculada. 
Entrei em contato com a direção de cada escola para confirmar a situação da professora iniciante (todas mulheres) e solicitei autorização para visitar a escola e conversar com a nova professora e sua tutora. Das cinco escolas, apenas uma recebeu uma professora que já tinha bastante experiência docente. Nas demais, todas as recém-chegadas eram professoras iniciantes na profissão, sendo duas delas sem nenhuma experiência anterior e duas com, no máximo, dois anos de experiência.

Visitei as quatro escolas públicas nos meses de abril e maio de 2014 e conversei com sete professoras de Educação Infantil, sendo quatro professoras iniciantes e as respectivas tutoras do período de práticas, com exceção de uma com quem não pude conversar por questões relacionadas ao seu horário de trabalho.

As escolas visitadas eram todas Centros de Educação Infantil e Primária - CEIP. A primeira localizada em uma das principais praças do centro da cidade de A Coruña num edifício antigo, grande e de arquitetura tradicional do início do século XX. Outra, também, localizada em A Coruña, na praça no bairro de Elviña, ocupa um terreno muito amplo e se trata de um edifício moderno lanos 1970) com largos corredores e três andares.

Em Santiago de Compostela, visitei uma localizada no centro da cidade que está instalada em um prédio bastante novo e grande, com amplos corredores e dois andares. A segunda visitada em Santiago fica em uma colina do bairro que the dá o nome. Trata-se de um espaçoso edifício de três andares com amplo pátio exterior que está ao lado de um complexo de instituições da Secretaria de Educação (Centro de Informática, Escola de Formação Profissional, entre outros).

Todas essas escolas trabalham com os níveis Educação Infantil e o equivalente aos primeiros anos do Ensino Fundamental e possuem espaços para secretaria, direção, sala de professores, biblioteca, sala do coordenador geral, sala do zelador, um hall de entrada amplo e parque infantil. Na Espanha, a infraestrutura básica das escolas públicas está determinada pela Lei Orgânica de Educação, sendo a mesma para todas as comunidades autônomas que podem ampliar o básico determinado pela lei. Nos seus corredores, estavam expostos trabalhos dos alunos, havia exposições temáticas alusivas a datas comemorativas e a projetos trabalhados na época, informações às famílias, 
prestação de contas. Em uma delas, havia, também, exposição de livros no hall de entrada.

As professoras entrevistadas assinaram autorização para uso de seus depoimentos, com exceção de uma das tutoras (PROFESSORA 2), que só pôde me atender muito rapidamente. Os depoimentos foram gravados, com exceção de outra das tutoras que pediu para não ser gravada, pois ficaria inibida. Neste texto, as professoras serão identificadas apenas por números atribuídos a elas, de acordo com a ordem cronológica com que as entrevistas foram realizadas.

As entrevistas foram guiadas por roteiros diferentes para as professoras e para as tutoras, mas se desenvolveram como conversas informais que, muitas vezes, extrapolaram o roteiro. Com as professoras iniciantes, a entrevista girou em torno de como estava sendo o acompanhamento; como eram as atividades de formação; que considerações podia a professora fazer sobre a contribuição desse período para o seu desenvolvimento profissional; que dificuldades enfrentou; o que mais ajudou a superá-las. No caso das professoras tutoras foi perguntado como era o acompanhamento à professora iniciante; como eram as atividades de formação; quem as organizava e oferecia; como foi o seu início de carreira sem tutoria.

As professoras iniciantes entrevistadas (PROFESSORAS 1, 3, 5 e 7) tinham idade entre 25 e 29 anos, estudaram nas universidades de Santiago de Compostela, A Coruña e Ourense. Duas delas não possuíam nenhuma experiência anterior na docência (PROFESSORAS 1 e 3); uma possuía experiência de trabalho durante um ano em uma creche privada (PROFESSORA 5) e outra possuía experiência de dois anos como professora substituta em Educação Infantil na rede pública (PROFESSORA 7).

A partir dessas conversas, foi possível perceber os matizes dados à lei no cotidiano das escolas. Apesar de um único contato, com exceção de uma das professoras que acompanhei em outra entrevista já na sua vaga definitiva em outra escola, as conversas foram produtivas e permitiram refletir sobre as tensões cotidianas que atravessam as relações e a necessidade de concretizar as determinações legais. Duas questões me chamaram especialmente a atenção e passo a discuti-las a seguir. 


\section{Tensões entre o prescrito e o vivido}

Conforme visto no início deste artigo, a Lei Orgânica (2006) espanhola afirma a necessidade de dar atenção à formação continuada dos docentes e apoio no seu primeiro ano de carreira profissional. $\bigcirc$ Decreto $n^{\circ} 227$, de 23 de dezembro de 2007, versa no seu capítulo V do título III (Do sistema de ingresso) sobre o chamado período de práticas dos novos professores, e, no seu artigo 101, trata da incorporação à docência nas escolas públicas, em forma de acompanhamento dos professores e professoras no primeiro ano (entre três meses a um ano) de exercício profissional por colegas com mais experiência, preferencialmente do mesmo nível de atuação, que cumprem a função de tutores. Esse período poderá incluir também cursos de formação. $\bigcirc$ edital para o concurso público na Galícia, publicado em 2013, obedece a essas determinações e as detalha para normatizar a realização do processo com os aprovados nas provas de seleção.

Se estamos atentos ao nome do título III da Lei "Do sistema de ingresso", em que se inserem os procedimentos relacionados aos professores e professoras que ingressam no magistério público, já vislumbramos que não se trata de um

43 programa de apoio aos docentes iniciantes, mas de um procedimento para completar a avaliação e a entrada dos profissionais na rede.

Essas disposições legais que limitam a iniciação docente a um período determinado de antemão para todos, que definem a designação do tutor por uma comissão integrada pelo chefe da supervisão regional, supervisores educacionais e diretores de escolas, e que atrelam esse período ao processo de seleção dos novos decentes, são consideradas por pesquisadores locais (EIRÍN; GARCÍA; MONTERO, 2009) como um processo burocrático que pouco contribui para o desenvolvimento profissional.

Esse período possui, certamente, um caráter administrativo-burocrático, necessário para cumprir os procedimentos de maneira que os novos professores e professoras completem o processo seletivo e possam ser efetivados no cargo. Ao entrevistar as professoras buscando saber o funcionamento na prática dessas disposições, percebi que, durante esse período, elas passam por experiências significativas e recebem apoio real das companheiras mais experientes, mas também têm que enfrentar desafios com pouca ou nenhuma orientação. Os mesmos pesquisadores que avaliam a proposição legal como burocrática advertem: 
Mantemos a ideia de que [...] a fase de práticas assinalada nos editais de concursos para docentes, pode ser uma boa oportunidade para reivindicar um período de iniciação à profissão e poder abordar o tema mais seriamente. Pensamos que a necessidade e a demanda são claras, existem exemplos nos países do nosso entorno [...] parece-nos evidente que investir recursos para a melhoria da formação dos professores nos seus primeiros anos de desempenho profissional, é uma boa estratégia de melhoria da qualidade do ensino. É necessário apenas vontade política para colocá-la em prática (EIRÍN; GARCÍA; MONTERO, 2009, p. 108, tradução minha).

No cotidiano das escolas visitadas, foi possível conhecer a complexidade da situação que não é definida nem pela letra da lei, nem apenas pelo componente burocrático que ela supõe. Na prática, o "período de práticas" se dá e é atravessado por inúmeros acontecimentos que vão conformando o processo e contribuindo mais, ou menos, para a formação das professoras iniciantes. Por exemplo, todas as professoras iniciantes entrevistadas demonstraram ter muito entusiasmo, identificação e afinidade com o trabalho docente, desejo de trabalhar e de acertar e todas consideraram a experiência boa, válida e rica de aprendizagens. Uma delas até relatou não ter tido dificuldade de nenhuma espécie.

Ainda assim, e, ao mesmo tempo, as professoras contaram ter passado por um período inicial bastante sofrido, quando, em muitos momentos, não sabiam o que fazer e tinham medo de não conseguir ser bem-sucedidas. Até mesmo aquelas que já possuíam uma pequena experiência anterior, relataram que, ao chegar à escola, sentiram medo, mas, ao mesmo tempo, muita vontade de realizar o seu trabalho; por isso, nenhuma delas pensou em abandonar a profissão nesse primeiro ano.

Entendo que as ações humanas são sempre muito mais complexas e vão muito além do que as leis ou documentos oficiais fixam, prescrevem ou pretendem. Essas ações, permeadas pelo contexto, valores, vontades, afetos, saberes, experiências, interesses dos envolvidos, tecem, no cotidiano, o modo como as professoras vão entrando na profissão, vão se tornando professoras, socializando-se e sendo socializadas, constituindo suas identidades docentes sempre em movimento. Nesse caso, estar na lei é básico e fundamental, mas não determina como as professoras iniciantes serão apoiadas. 
Aproximo-me desse universo com a ajuda de Certeau (1994) que me mostra que, para além das estratégias institucionalizadas, nós, pessoas comuns, vamos criando nossas formas de usar o que nos é oferecido. Nos seus estudos, Certeau (1994) vai desvelando o poder que as práticas cotidianas ganham, e mostrando como essas pessoas, vistas, muitas vezes como consumidoras passivas das determinações sociais, inventam maneiras de fazer diferentes das prescritas ou esperadas, por isso são chamadas de praticantes pelo autor.

Ele descreve o cotidiano como espaço/tempo de produção de distintas maneiras de manipular o contexto, e como, nessas ações cotidianas, são produzidas diversas e diferentes maneiras de compreender e de fazer, em processos que mostram os sujeitos se reapropriando do que está préfixado. Dessa forma, as práticas cotidianas e sua pluralidade, multiplicidade e criatividade são ressaltadas, revelando como os sujeitos inventam formas de organização das suas relações e o ambiente escolar.

É como praticantes que percebo e reconheço as professoras iniciantes e tutoras com quem conversei e os coletivos escolares que as receberam e dos quais faziam parte como praticantes, e, apurando mais, como praticantes pensantes, expressão de Oliveira (2012) para não nos deixar esquecer que 45 produzir, criar, inventar, fazer e pensar nunca se separam, e que a prática produz teoria e dela surgem novas práticas.

As professoras que conheci, iniciantes e tutoras, realizam práticas cotidianas de formação, acolhimento, cooperação e troca que vão muito além do previsto na lei. Mas poderia ser diferente e até o contrário. As professoras também poderiam obedecer burocrática e minimamente à Lei, preencher relatórios e formulários. De qualquer forma, são elas as praticantes não passivas, segundo Certeau, praticantes pensantes, segundo Oliveira, que vão imprimindo cor e sabor (de saber) à palavra limitada da Lei.

As histórias narradas mostram a vida que a lei adquire no cotidiano das escolas. Duas das professoras entrevistadas (PROFESSORAS 1 e 7) assumiram uma turma própria assim que chegaram à escola e suas tutoras eram professoras da mesma etapa da Educação Infantil, em turmas de quatro e de cinco anos. As outras duas iniciantes (PROFESSORAS 3 e 5) passaram o período de práticas como professoras de apoio, cumprindo várias funções: substituir professores; estar nas classes junto à professora titular para apoiá-la quando necessário; dar plantões na biblioteca; acompanhar as crianças na chegada e na saída do 
ônibus escolar; ministrar aula de informática, de jogos, e de psicomotricidade; estar com os alunos nos horários de atenção educativa, que é a alternativa às aulas de religião; ser corresponsável pela decoração das áreas comuns da escola de acordo com datas comemorativas e projetos desenvolvidos.

Uma das entrevistadas (PROFESSORA 3) que cumpriu a função de apoio, por exemplo, considerou a experiência como muito positiva, já que teve a oportunidade de aprender compartilhando as aulas com outras professoras (mas principalmente com a sua tutora - PROFESSORA 4), além de ter passado pelas diversas atividades realizadas na escola com as crianças, ter conhecido as características de todas as professoras e todas as crianças desse nível de ensino. Isso, segundo ela, permitiu conhecer melhor a estrutura da escola como um todo e experimentar diferentes formas de atuação pedagógica. Essa professora esteve nos primeiros 15 dias apenas observando a prática pedagógica das professoras de Educação Infantil em todas as turmas e, durante esse período de observação, elas destacavam aspectos do que faziam, mostravam o planejamento antes e discutiam com ela o desenvolvimento das atividades. Para ela, "[...] o primeiro ano de todos os professores que estão começando a sua carreira deveria ser nesta função de apoio [...]" (PROFESSORA 3) e sua tutora (PROFESSORA 4) concorda, pois teve a mesma experiência no seu período de práticas.

A outra professora iniciante, que também assumiu o papel de apoio durante o período de práticas (PROFESSORA 5), já relata uma experiência diferente. Sua tarefa principal era substituir, em classe, duas professoras da equipe gestora $^{3}$, quanto tinham que exercer suas funções administrativas. Dessa forma, quando estava com as turmas, não tinha o acompanhamento das professoras titulares e sua maior dificuldade era ser responsável pelos grupos em alguns momentos, tendo que dar continuidade ao trabalho que as professoras titulares estavam desenvolvendo, mas não tendo discutido o planejamento nem as atividades com elas. Nesses momentos, dedicava-se a fazer jogos e atividades de artes plásticas com os alunos e se sentia frustrada por não fazer o trabalho pedagógico completo. Sentiu-se perdida até o momento em que as titulares perceberam sua angústia e sua dificuldade e retomaram a orientação ao seu trabalho, dando-lhe tarefas específicas que complementavam o trabalho que elas vinham fazendo com a turma.

A professora descreveu esse momento como muito problemático, mas que foi superado com o diálogo com as companheiras, com a proposta de 
mudança no tipo de trabalho e com a decisão de ela aceitar a situação de não ser a professora titular. Ela diz ter sobrevivido, usando o mesmo termo com que Huberman (2000) descreve essa primeira fase da carreira docente.

A professora abre mão do enfrentamento; de um lado, pela tentativa de diálogo que foi estabelecida pelas colegas; de outro lado, por entender que sua situação na escola era passageira, que logo estaria com sua matrícula definitiva em outra escola e principalmente porque ela queria ser aprovada e, para isso, dependia da tutora. Na minha compreensão, agindo assim a professora se utilizou do que Certeau (1994) chama de tática: procedimentos minúsculos e cotidianos que não se conformam e alteram a disciplina dada pelo contexto e são a contrapartida dos praticantes aos processos mudos de ordenação sóciopolítica.

A constatação da ambiguidade, contradições e complexidade dessa situação, no sentido dado por Morin (1996) do que é tecido junto com diferentes fios que se transformam numa só coisa, pode ser observada em outros aspectos do período de práticas: o primeiro se refere ao trabalho das tutoras e sua relação com as professoras; o segundo está relacionado com a situação exposta nos parágrafos anteriores, ou seja, à avaliação do trabalho das 47 novas professoras; e o terceiro às atividades de formação continuada. São estes aspectos que passo a discutir a seguir.

Em relação ao trabalho das tutoras, está previsto na legislação que, para exercer o papel de tutor, o professor ou a professora deve ser um(a) profissional experiente, preferencialmente da especialidade e do nível de ensino correspondente aos do professor ou da professora em práticas; deve ser escoIhido pela comissão qualificadora formada pela Secretaria de Educação. Esse(a) profissional tem, como função, assessorar, informar e avaliar o(a) funcionário(a) em práticas sobre a organização e funcionamento da escola, sua participação nas atividades, e ainda sobre a programação didática das áreas de conhecimento, o planejamento de aula e a avaliação dos alunos.

Ao final do período de práticas, o tutor ou a tutora deve emitir um relatório sobre todos os dados considerados de interesse sobre o professor ou professora em práticas e remetê-lo à comissão já mencionada. Esses tutores e tutoras recebem 30 horas equivalentes a atividades de formação que podem ser usadas na sua progressão funcional. 
Nas escolas visitadas, as tutoras (PROFESSORAS 2, 4 e 6) foram escoIhidas pela própria equipe de professoras do ciclo da Educação Infantil que recebia a novata, ou seja, foi uma decisão coletiva dos grupos das escolas. As tutoras escolhidas não tinham um horário específico para estar com as professoras em práticas (o que todas as entrevistadas julgaram ser necessário), mas como eram do mesmo nível de ensino encontravam-se nas reuniões semanais já mencionadas.

Para as professoras iniciantes, a reunião semanal representava um momento a mais para esclarecer dúvidas, pedir opiniões, receber orientações e sugestões. Segundo as tutoras entrevistadas, não há uma obrigação específica, e a função de tutora não pressupõe um trabalho a mais, é uma atividade que pode fluir, informalmente, e dentro das atividades já previstas, dependendo do tipo de relação que se estabelece, da disposição da tutora e do grupo em compartilhar conhecimentos e experiências e de orientar a nova colega, e ainda da disposição da novata em aprender. Todas as professoras disseram que a conversa, as orientações, a entrega de materiais, e os esclarecimentos se davam o tempo todo de modo informal em atividades cotidianas.

Eirín, García e Montero (2009) avaliam que entre tutora e professora pode, muitas vezes, ser estabelecido um vínculo hierárquico, numa relação tradicional ensinante-transmissor e aprendente-subordinado. Porém, matizam essa afirmação e se aproximam mais do que aconteceu nas escolas visitadas, de acordo com o depoimento das professoras entrevistadas:

[...] uma leitura um pouco mais profunda se pode ver esta relação como uma oportunidade para facilitar o crescimento profissional do professor iniciante proporcionando-the oportunidades de observar e comprometer-se com boas práticas educativas, colocá-las em prática, receber ajuda y assessoramento em forma de feedback com novas ideais e possibilidades de melhora (EIRÍN; GARCÍA; MONTERO, 2009, p. 103, tradução minha).

Indo um pouco além, encontro mais uma vez Certeau (1994) e posso apreciar as professoras e suas tutoras como sujeitos que, no seu cotidiano, vão tecendo laços e inventando as suas maneiras de fazer a socialização e inserção das novatas, com as tensões que são peculiares a essa relação. Os próximos aspectos comentados, o poder de avaliação das tutoras e a formação continuada, demonstram essa tensão e sua complexidade. 
Um dos pontos de forte tensão inerentes à relação entre tutoras e professoras se refere à avaliação das novas professoras, pois, no edital publicado pela Xunta de Galícia em 2013 convocando o concurso de provas e títulos para professores, o período de práticas estava previsto como uma fase de duração de quatro meses, definido, em conformidade com o real Decreto de 2007, como "[...] parte do procedimento seletivo e tem por objeto a comprovação de que o aspirante possui as capacidades didáticas necessárias para o exercício da docência" (GALíCIA, 2013 , p. 990, tradução minha). Para isso, o edital já previa dar ao tutor ou tutora o poder de controlar o desempenho do(a) novo(a) professor ou professora preenchendo um formulário sobre suas atividades, e ainda de produzir um relatório com parecer final sobre sua aprovação ou não como funcionário(a) efetivo(a).

Ainda segundo o edital, caberia também à direção da escola avaliar a contribuição e inserção do(a) novo(a) professor(a) às atividades da instituição. Todos esses documentos deveriam ser entregues à comissão qualificadora para avaliação e parecer final. Se o(a) funcionário(a) em práticas não fosse aprovado(a), nesse período, teria outra chance no ano letivo seguinte para realizar as práticas.

49 Por parte dos(as) docentes em práticas, deveria ser elaborado um relatório-memorial ao final do período, no qual fariam uma avaliação global da sua atividade, assim como das dificuldades encontradas e dos apoios recebidos. Esse memorial consistia em relatar como foi o período de práticas, como realizavam as rotinas na classe, as principais dificuldades, imprevistos surgidos, conhecimentos sobre os documentos da escola, uma avaliação geral do trabalho realizado. Para elaborar esse relatório, as professoras entrevistadas não receberam modelo tampouco orientações muito detalhadas e específicas por parte da Secretaria de Educação, apenas alguns pontos que deveriam abordar, além de apoio e informações da direção das escolas.

A professora que vivenciou essa situação delicada e desfavorável anteriormente comentada, relatou que tentou se adaptar, pensando também que este era um momento passageiro devido à sua condição de provisória e que ainda estava em processo seletivo. Dessa forma, percebo que um período que poderia ser tomado apenas como apoio ao desenvolvimento profissional docente, ao ser definido como parte da seleção, passa a ter as características de uma avaliação classificatória: vigiar, controlar, com relações de poder hierárquicas que geram tensões nessa convivência já que, sendo companheira de 
trabalho e responsável por orientar, a tutora tem também a função de aprovar ou não o trabalho da professora iniciante. Vincula, portanto, a avaliação à ideia de eficiência reforçando sua dimensão de controle.

Nesse sentido, é de se destacar que a importância dedicada, na Lei, à formação dos profissionais iniciantes está associada à avaliação do seu trabatho, ainda como candidatos e candidatas a uma vaga efetiva na rede pública. Isto quer dizer que esse período não é encarado oficialmente apenas como um período de aprendizagem, adaptação e socialização do novo profissional, mas, fundamentalmente, o contrário: é um período quando o novo professor ou professora tem que demonstrar conhecimentos e "capacidades didáticas necessárias para a docência."

Uma das tutoras (PROFESSORA 4) considera que o objetivo da Lei que determina o período de práticas é mesmo controlar e avaliar o trabalho e a ałuação da profissional novata, porém considera que, na prática, é uma oportunidade de aprendizagem e que o tutor deve ser alguém de confiança que a apoie e seja uma referência que pode esclarecer dúvidas e trocar experiências.

apoio e a troca de experiências que menciona a tutora entrevistada são elementos da formação continuada, da atividade de companheirismo na relação entre tutora e professora, que acontecem ao mesmo tempo em que as atividades hierarquizadas de controle e avaliação.

No edital do concurso para o professorado novato, a única atividade prevista era a realização obrigatória de um curso de formação de língua galega, com 20 horas de duração, programado pelo Serviço de Formação de Professores da Secretaria de Educação, com o objetivo de que os novos docentes pudessem desenvolver plenamente suas atividades em língua galega. Esse curso foi considerado irrelevante por todas as professoras por não contribuir com o trabalho pedagógico. Houve, ainda, no decorrer do período de práticas, algumas ofertas de cursos pela Secretaria como: "Tecnologias da Informação e da Comunicação" e "Trabalho com Papel Reciclado."

Na prática, em todas as escolas visitadas as principais atividades e oportunidades de formação continuada foram as reuniões semanais entre as professoras, que ocorrem no turno da tarde $\mathrm{em}^{4}$ todas as escolas, para planejamento, avaliação e organização das salas de aula e de materiais. Como nas redes escolares brasileiras que conheço e que possuem essa dinâmica de reuniões pedagógicas dentro da carga horária semanal, os grupos de docentes 
usam esse momento de formas diferentes: em algumas escolas para realizar um trabalho de planejamento coletivo e troca de experiências; em outras, cada professora aproveita o tempo para elaborar materiais para sua turma, corrigir trabalhos etc.

Em uma das escolas visitadas, presenciei as professoras individualmente em suas salas de aula corrigindo trabalhos e organizando exercícios para seus alunos e alunas. Em outra das escolas em alguns destes dias de reunião são organizadas jornadas de troca de conhecimentos, em que cada professor ou professora ensina aos colegas algo que domina com mais propriedade. Nessa escola, estava sendo desenvolvido, também, um "Programa de Reforço e Orientação Acadêmica", orientado pela Secretaria de Educação para atender às crianças que tinham necessidade, do qual a professora (PROFESSORA 3) iniciante participava.

Porém, em nenhuma das entrevistas, foi mencionado que essas reuniões eram também momentos de reflexão coletiva sobre a prática e/ou da realização de estudos a partir disso. Imbernón (1994) destaca a reflexão sobre a própria prática mediante análise, compreensão, interpretação e intervenção sobre ela como um dos três grandes eixos para a formação de professores e 51 professoras iniciantes. A ideia de reflexão, porém, não se limita a uma atitude tampouco a um processo individual.

Zeichner (2008), que participou do movimento a favor da reflexão sobre a prática na formação de professores e professoras como forma de combater o ensino meramente técnico, adverte que, a partir dos anos 1980, a reflexão tornou-se um slogan no campo da formação de professores e, com isso, começou a perder seu significado específico, já que o termo, ao ser abraçado por todos, deixa de expressar a diferenciação das posições ideológicas que estão por trás do seu uso. A reflexão sobre a prática que defendo, com o auxílio de Zeichner (2002), e da qual senti falta nos depoimentos das professoras, se refere mais uma vez à concepção de professores e professoras como praticantes pensantes, capazes de criar e não reproduzir. Zeichner (2002) advoga a reflexão como processo coletivo, criativo e não técnico ou submisso a currículos e práticas predeterminadas para os professores, ou seja, numa concepção emancipatória. Neste sentido, é uma atitude que: valoriza a prática sobre a qual se reflete; em que se reflete sobre aspectos filosóficos da educação, suas finalidades e aspectos éticos; em que se considera o contexto social e institucional nas 
reflexões; e se realiza a reflexão como forma de apoiar e realizar a luta por justiça social mais ampla na educação e na sociedade.

Talvez por não se tratar de um programa organizado de apoio aos novos docentes que atenda às suas necessidades oferecendo-lhes desenvolvimento e formação profissional, o procedimento espanhol, por mais que seja transformado e inventado no cotidiano por suas praticantes, não é suficiente para contribuir com a organização de grupos de reflexão coletiva.

\section{Tensões entre pesquisas/propostas e realidade: dificuldades antigas ainda presentes}

Outra tensão vislumbrada ao conversar com as professoras e conhecer suas atividades e relações, durante o período de práticas, está relacionada às dificuldades relatadas por elas que equivalem às mesmas dificuldades encontradas por docentes iniciantes há muito tempo.

Pesquisadores que investigam a formação continuada do professorado iniciante já mencionados no início deste artigo (IMBERNÓN, 1994; MARCELO GARCIA, 1999; HUBERMAN, 2000; GUARNIERI, 2005; EIRÍN; GARCÍA; MONTERO, 2009; NONO, 201 1), são unânimes em afirmar a necessidade de que essa fase da carreira docente receba especial atenção em relação às condições de inserção, formação, acompanhamento e acolhimento dos novos profissionais, como medida que contribui para a melhor qualidade da educação, já que, nela, os(as) profissionais encaram desafios e tensões específicas desse momento. As dificuldades encontradas por novos(as) professores e professoras constituem tema recorrente nas pesquisas publicadas.

Essas dificuldades e o prejuízo que podem trazer, poderiam ser abordadas em duas importantes dimensões: a) para cada um na sua relação com a profissão e sua constituição como sujeito ativo da sua própria formação; e b) para a escola, como espaço de construção coletiva de uma educação pautada nas necessidades dos estudantes e visando seu sucesso.

Entre os primeiros pesquisadores a se voltarem para essa fase da carreira está Veenmann, que, em 1984, já fazia um estudo com o levantamento de dificuldades específicas desse período. Ao entrevistar as professoras iniciantes em um país onde existe uma legislação que determina um acompanhamento especial a esta fase, pude, com surpresa, relacionar as dificuldades relatadas 
por elas com as listadas por esse pesquisador há 30 anos. Dos 23 pontos listados por Veenman (1988), encontro coincidência em, pelo menos, 11 deles.

As principais dificuldades referidas pelas professoras iniciantes que ficaram como titulares de turmas de Educação Infantil foi o fato de estar, pela primeira vez, diante de um grupo considerado grande para os padrões locais atualmente (26 alunos em média) e pensar no que fazer com todas as crianças ao mesmo tempo, que atividades propor; como estabelecer a rotina e a disciplina para que os alunos obedecessem às normas de convivência; as reuniões com as famílias; os primeiros momentos de contato com a escola no papel de professoras e com as responsabilidades que isso significa. Uma delas relatou dificuldades materiais e de infraestrutura inicialmente, por causa da sala de aula que não estava adaptada ao seu nível de idade. Há nas escolas públicas em Galícia o costume de a professora de Educação Infantil começar com o grupo de alunos aos três anos e acompanhá-los até o final desse nível, com cinco anos.

As duas professoras (PROFESSORAS 1 e 7) que assumiram turmas próprias não tiveram essa oportunidade e estiveram com turmas de quatro e cinco anos, tendo relatado esse fato como uma dificuldade a mais. Uma professora 53 (PROFESSORA 5) que ficou como apoio relatou dificuldade com o planejamento, com as companheiras e apoio inadequado.

De maneira geral, a inserção e compreensão do meio laboral e suas relações constituíram uma dificuldade inicial para as professoras, e principalmente o encontro com o mundo da escola real explicitando sua diferença em relação àquele estudado na universidade: "[...] estudar este mundo teoricamente está bem, mas vê-lo funcionar, participando de um conselho de classe, por exemplo, é distinto, é tudo novo [...]", disse uma das professoras iniciantes de Santiago (PROFESSORA 5, 2014). Com essas palavras, a professora expressa o que Veenman (1988, p. 40) denomina "[...] choque de realidade $[\ldots] "$, conceito que "[...] indica o colapso dos ideais missioneiros elaborados durante a formação inicial do professorado com a realidade crua e dura da vida cotidiana na classe."

Como forma de superar as dificuldades expostas, as professoras relataram que buscaram aprender com elas, estudar, trabalhar muito, e também procuraram o apoio das companheiras (tanto da tutora quanto de outras professoras) e da direção da escola (que disseram sempre ter recebido). 
Conforme me referi antes, essas dificuldades coincidem com algumas das apontadas por Veenman (apud VEENMAN, 1988) há 30 anos: disciplina na classe; relação com os pais; tratamento das diferenças individuais dos alunos e alunas; utilização de diferentes métodos de ensino; organização do trabalho na classe; insuficiência de materiais; planejamento do processo de ensino-aprendizagem; conhecimento das normas e hábitos da escola; inadequação do equipamento e mobiliário escolar; elevado número de alunos.

Apesar de, nos trinta anos que separam a publicação de Veenman das entrevistas realizadas, a pesquisa sobre essa área ter aumentado e avançado; e apesar de, na Espanha, a legislação prevê o período de práticas com atenção especial aos professores iniciantes, no cotidiano ainda se processam os mesmos desafios.

Uma possibilidade de compreensão dessa situação que se repete, relaciona-se ao que Eirín, García e Montero, (2009) apontam como limitação da proposta do período de práticas, avaliando que ela está mais próxima de um trâmite burocrático-administrativo, como um período de espera para assumir, plenamente, a condição de funcionário público, do que de um programa de apoio aos novos professores e professoras como forma de melhorar a aprendizagem sobre o processo de ensino e evitar que esses profissionais abandonem a profissão. Esses pesquisadores acreditam que esse apoio deve ser parte de um processo mais amplo que vai desde a formação inicial e segue em movimento permanente de revitalização, cuja criação defendem, pois entendem a atenção especial aos primeiros anos de docência como uma fase de contínuo apoio ao professorado, indo muito além do que estabelece a lei em seu país.

Segundo pesquisa da Organização para a Cooperação e Desenvolvimento Econômico - OCDE - realizada em 2008 (OCDE, 20 1 2), na maioria dos países há programas de apoio aos professores iniciantes, cuja qualidade e as atividades variam enormemente, desde apenas uma introdução administrativa até os programas de colaboração de vários anos de duração. Na pesquisa, o Brasil aparece em último lugar, nesse quesito, pela falta de programas institucionais.

Podemos encontrar, em outros pesquisadores espanhóis /CORTÉS GONZÁLEZ; LEITE MÉNDEZ; RIVAS FLORES, 2014), uma segunda possibilidade de compreensão sobre a presença de dificuldades tão antigas no cotidiano das professoras iniciantes hoje. Eles focam seu interesse na primeira fase da 
docência, investigando como a identidade docente vai se constituindo durante esse período e na formação inicial. Acreditam que não é possível pensar na docência sem pensar a história de vida e as vivências dos docentes em diferentes contextos, institucionais ou não, pois é a partir delas que vai configurando sua prática e seu pensamento. $\bigcirc$ grupo de novos professores e professoras pesquisado por eles expressou, em suas narrativas, a complexidade das experiências profissionais e pessoais de um professor nessa primeira fase da carreira.

Também nesse sentido aponta Jónsdóttir (2014), que realizou pesquisa com narrativas de professores sobre os seus cinco primeiros anos de trabatho destaca a decisiva influência que as experiências vividas pelos professores desde a infância possuem na atividade docente. A pesquisadora reafirma a ideia de que é preciso apoiar os professores nos seus primeiros anos de atuação e faz algumas recomendações para a realização desse apoio no primeiro ano: oferecer um ombro amigo, um ouvido para escutar e orientar sobre a organização cotidiana do trabalho.

As duas pesquisas não nos deixam esquecer que a etapa inicial da carreira é delicada, não apenas pela complexidade de conhecimentos e aprendizagens necessários, mas também por ser uma fase de inseguranças, 55 de questionamentos, dúvidas, desafios pessoais para os novos professores e professoras. Portanto, a formação, nessa fase, ou em qualquer outra, não pode ser apenas técnica e o acompanhamento não pode se restringir ao desenvolvimento de habilidades práticas.

As principais dificuldades apontadas pelos estudiosos anteriormente mencionados referem-se a aspectos relacionados às relações interpessoais e culturais; à organização do trabalho pedagógico; e ao contexto político-institucional. Entendo que esses três aspectos também coincidem com as dificuldades apresentadas pelas professoras entrevistadas.

Compreendendo o papel dos professores e professoras como fundamentalmente político, visto que está relacionado aos ideais formativos de uma comunidade, esses aspectos que resumem as dificuldades apontadas pelos estudiosos e pelas professoras não soam, para mim, como desafios a serem superados a partir de análises e ações presididas por uma racionalidade técnica.

Para além de serem questões de ordem técnica, elas demandam ética, ação política e ação/reflexão/ação sobre o contexto e sobre sua prática, 
nos mesmos moldes discutidos por Zeichner (2002) e já apresentados aqui anteriormente. Essas demandas, para serem satisfeitas, precisam mais do que uma lei que institua um período de práticas e do que a boa vontade das professoras. Precisam da organização de um programa completo e longitudinal de apoio aos docentes. Neste sentido, expresso minha concordância com Esteban (2001, p. 26) ao afirmar que "[...] formar professores e professoras não é tarefa exclusivamente técnica, é sobretudo uma ação ética [...]" e, com Pimenta (2002, p. 42), quando defende para o professorado a necessidade de "[...] conhecimento e informação sobre o trabalho, sobre aquilo que se faz (visão de totalidade, consciência ampla das raízes, dos desdobramentos, das implicações do que se faz para além da situação; das origens; dos porquês e dos para quê)."

Penso que as duas possibilidades de entender este fenômeno estão relacionadas entre si: as dificuldades encontradas estão vinculadas às crenças, concepções, formas de relação, saberes das professoras, questões que não se superam em um curto período de tempo, especialmente se esse período está vinculado à avaliação dos docentes. Um período que será melhor ou pior, dependendo das pessoas envolvidas, iá que as funções tão detalhadas e formalizadas na legislação, e confirmadas pelo edital do concurso na Galícia, são, na prática, realizadas da forma possível nos cotidianos das escolas. A existência de um programa de acolhimento, inserção e formação garantias, com procedimentos que oferecessem mais segurança e subsídios aos professores iniciantes para realizar seu trabalho, poderia minimizar tais dificuldades.

Porém, vejo ainda que as duas possibilidades por mim levantadas (necessidade de formação ética e reflexiva e falta de programa) estão vinculadas a um determinado modelo de conceber e realizar/produzir a formação docente, o processo de ensinar e aprender e a educação: a racionalidade técnica, que pensa essas atividades como realização de habilidades e competências, e os professores como aplicadores de teorias aprendidas na universidade e de planejamentos realizados por outros. Trata-se de uma concepção e um modelo bastante criticado em textos acadêmicos, mas que precisa ser superado também no cotidiano.

Pelo testemunho das entrevistadas, pode-se concluir que, prever na Lei um período de adaptação, é importante, mas o que conta, na prática, é a disposição de compartilhar o trabalho e as experiências (das duas partes), de dialogar, de fazer um trabalho coletivo; por parte da escola e das professoras 
mais experientes, de desejar que a nova professora tenha sucesso, que faça um bom trabalho com o alunado; e, por parte da professora iniciante, de estar aberta a aprender, de perguntar, revelando também o desejo de fazer um bom trabalho com as crianças. Para além das designações legais e das condições objetivas do trabalho e da escola lque comparadas à realidade brasileira podem ser consideradas boas em função da carga horária vinculada exclusivamente a uma escola e à infraestrutura dos centros educativos), o que fez a diferença, nesses casos foi o compromisso existente com a aprendizagem e o sucesso dos alunos, por parte da escola e por parte das novas professoras.

Com isso, é possível pensar que a presença da exigência legal pode ser um ponto de partida para que exista alguma possibilidade de formação e apoio, e também para reivindicar um programa completo, que ofereça condições para um desenvolvimento profissional autônomo e emancipatório.

\section{Notas}

1 Lei Orgânica para a Melhoria da Qualidade Educativa - LOMCE, de 10 de dezembro de 2013. Modifica a Lei Orgânica de Educação 2/2006, de 3 de maio de 2006.

2 Real Decreto $n^{\circ} 276$, de 23 de fevereiro de 2007, que regulamenta o ingresso, acesso e aquisição de novas especialidades nos corpos docentes de todas as comunidades autônomas e no capítulo V do título III trata da fase de práticas - artigos 29 a 31 .

3 Na Espanha, os professores e professoras eleitos para as funções de gestão diminuem a carga horária letiva, mas não deixam de dar aulas.

$4 \bigcirc$ horário de trabalho das professoras da Educação Infantil e dos primeiros anos do Ensino Fundamental é todas as manhãs em aulas e uma tarde por semana para atividades a serem realizadas fora da sala de aula. As professoras trabalham em, apenas, uma escola.

\section{Referências}

CERTEAU, Michel de. A invenção do cotidiano: 1 As artes de fazer. 10. ed. Tradução Ephraim Ferreira Alves. Petrópolis: Vozes, 1994.

CORTÉS GONZÁLEZ, Pablo; LEITE MÉNDEZ, Analía; RIVAS FLORES, José Ignacio. Un enfoque narrativo de la identidad profesional en el profesorado novel. Tendencias Pedagógicas, Madrid, n. 24, p. 199-214, 2014. 
EIRÍN NEMIÑ̃A, Raúl; GARCÍA RUSO H. Ma; MONTERO MESA, Lourdes. Profesores Principiantes e Iniciación Profesional. Revista Profesorado, Granada, v. 13, n. 1, p. 101115, jan./abr. 2009.

ESPAÑA. Ley Orgánica de Educación 2/2006, del 3 de mayo de 2006. Ministerio de Educación, Cultura y Deporte. Boletín Oficial Del Estado, Madrid, 4maio 2006, n. 106. Disponível em:www.boe.es/boe/dias/2006/05/04/pdfs/A17158-17207.pdf. Acesso em: 3 abr. 2014.

. Real Decreto n² 276, de 23 defebrero de 2007. Aprova regulamento de ingresso, acesso e aquisição de novas especialidades e regime de práticas dos corpos docentes. Ministerio de Educación e Ciencia. Boletín Oficial del Estado, Madrid, 2 mar. 2007, n. 53, p. 8915-8938. Disponível em: www.boe.es/boe/dias/2007/03/02/pdfs/A0891508938.pdf. Acesso em: 3 abr. 2014.

Ley Orgánica para la Mejora de la Calidad Educativa 8/2013, de 10 de diciembre de 2013. Ministerio de Educación e Ciencia. Boletín Oficial del Estado, Madrid, 10dic. 2013, n.295, p. 97858-97921. Disponível em: www.boe.es/diario_boe/txt. php?id=BOE-A-2013-12886. Acesso em: 3 abr. 2014.

ESTEBAN, Maria Teresa. O que sabe quem erra? 2. ed. Rio de Janeiro: DP\&A, 2001.

GALICIA. ORDEN de 23 de marzo de 2013. Oposiciones y Concursos. Consellería de Cultura, Educación y Ordenación Universitaria. Diario Oficial de Galicia: Santiago de Compostela, 4 de abr. 2013 n. 65, p. 9865-9916.Disponível em http://www.xunta.es/ dog/Publicados/2013/20130404/AnuncioG0 164-250313-0003_gl.html. Acesso em: 7 abr. 2014.

GUARNIERI, Maria Regina. O início da carreira docente: pistas para o estudo do trabalho do professor. In: GUARNIERI, Maria Regina (Org.). Aprendendo a ensinar: o caminho nada suave da docência. 2. ed. Campinas: Autores Associados, 2005.

HUBERMAN, Michael. O ciclo de vida profissional dos professores. In: NÓVOA, António (Org.). Vidas de professores. 2. ed. Porto (Portugal): Porto Editora, 2000.

IMBERNÓN, Francesc. La formación y el desarrollo profesional del profesorado: hacia una nueva cultura profesional. Barcelona: Graó, 1994.

JÓNSDÓTTIR, Lilja. Hitching one's wagon to a star: narrative inquiry into the first five years of teaching in Iceland. In: EUROPEAN CONFERENCE ON EDUCATIONAL RESEARCH ECER, 2014, Porto (Portugal). Anais eletrônicos... Porto: European Educational Research Association, 2014. Disponível em: http://www.eera-ecer.de/ecer-programmes/conference/19/contribution/32589/. Acesso em: 5 set.2014. 
Inserção de professoras iniciantes em escolas públicas: um olhar sobre as práticas na Espanha

MARCELO GARCIA, Carlos. Formação de professores. Para uma mudança educativa. Porto (Portugal): Editora Porto, 1999.

MORIN, Edgar. Ciência com consciência. Tradução Maria Alexandre. Rio de Janeiro: Bertrand Brasil, 1996.

NONO, Maévi Anabel. Professores iniciantes: o papel da escola em sua formação. Porto Alegre: Editora Mediação, 2011.

ORGANIZAÇÃO Para a Cooperação e Desenvolvimento Econômico - OCDE. ¿Qué se puede hacer para ayudar a los profesores noveles?. Teaching in Focus, v. 2, n. 2, sep. 2012. Disponível em http://www.oecd.org/edu/school/TiF\%2O(2012)-N\%C2\%BO2\%20 (esp)-v2.pdf. Acesso em: 25 maio 2014.

OLIVEIRA, Inês Barbosa de. Aprendizagem ensino de qualidade nas escolas: a produção de conhecimento em didática e em currículo pelos praticantes pensantes nos/dos cotidianos. ENCONTRO NACIONAL DE DIDÁTICA E PRÁTICAS DE ENSINO (ENDIPE), 16; 2012 , Campinas. Anais... Campinas: Universidade Estadual de Campinas, 2012. Junqueira \& Marin, 2012. (Livro 1).

PIMENTA, Selma Garrido. Professor reflexivo: construindo uma crítica. In: PIMENTA, Selma

59 Garrido (Org.). Professor reflexivo no Brasil: gênese e crítica de um conceito. 2. ed. São Paulo: Cortez, 2002.

PROFESSORA 1. Entrevista. A Coruña (Espanha), 29 abr. 2014.

PROFESSORA 2. Entrevista. A Coruña (Espanha), 29 abr. 2014.

PROFESSORA 3. Entrevista. Santiago de Compostela (Espanha), 29 abr. 2014.

PROFESSORA 4. Entrevista. Santiago de Compostela (Espanha), 29 abr. 2014.

PROFESSORA 5. Entrevista. Santiago de Compostela (Espanha), 30 abr. 2014.

PROFESSORA 6. Entrevista. Santiago de Compostela (Espanha), 6 maio 2014.

PROFESSORA 7. Entrevista. A Coruña (Espanha), 8 maio 2014.

SAMPAIO, Marisa Narcizo. Os caminhos que fazemos ao caminhar: diálogos entre professoras e coordenadoras a partir de registros diários de aula. 2008. 202f. Tese (Doutorado em Educação) - Programa de Pós-Graduação em Educação, Universidade Federal Fluminense, Niterói, 2008. 
VEENMAN, Simon. El proceso de llegar a ser profesor: un análisis de la formación inicial. In: VILLA, Aurelio (Coord.). Perspectivas y problemas de la función docente. Madrid: Narcea Ediciones, 1988.

ZEICHNER, Kenneth. Formando professores reflexivos para uma educação centrada no aprendiz: possibilidades e contradições. In: ESTEBAN, Maria Teresa; ZACCUR, Edwiges Teresa (Org.) Professora-pesquisadora: uma práxis em construção. Rio de Janeiro: DP\&A, 2002.

Uma análise crítica sobre a "reflexão" como conceito estruturante na formação docente. Educação \& Sociedade, Campinas, v. 29, n. 103, p. 535-554, maio/ago. 2008. Disponível em: http://www.cedes.unicamp.br. Acesso em: 24 set.2014.

Profa. Dra. Marisa Narcizo Sampaio Universidade Federal do Rio Grande do Norte | Natal Departamento de Práticas Educacionais e Currículo Programa de Pós-Graduação em Educação Grupo de Pesquisa Dialogicidade, Educação de Pessoas Jovens e Adultas e Práticas Culturais Pesquisa Financiada pela CAPES | Processo n 10904131 E-mail | marisamns@gmail.com 